\title{
Plasma adropin in exercised horses: a pilot study
}

\author{
Sylwester Kowalik', Witold Kédzierski², Iwona Janczarek ${ }^{3}$ and Izabela Wilk³ \\ 1 Department of Animal Physiology, Faculty of Veterinary Medicine, University of Life Sciences in Lublin, Lublin, Poland \\ 2 Department of Biochemistry, Faculty of Veterinary Medicine, University of Life Sciences in Lublin, Lublin, Poland \\ 3 Department of Horse Breeding and Use, Faculty of Animal Biology and Breeding, University of Life Sciences in Lublin, Lublin, Poland
}

\begin{abstract}
Summary: The role of adropin on energy metabolism in horses is still not fully known. We aimed to evaluate the effect of exercise on blood plasma adropin concentrations in horses. A total of 28 horses were included in the study. Twenty three-year-old purebred Arabian horses were involved in race training and eight Polish Konik stallions aged five to ten years were used as draft horses. The race horses were investigated both during the gallop at a speed $6-7 \mathrm{~m} / \mathrm{s}$ and $10-12 \mathrm{~m} / \mathrm{s}$. The draft horses worked in harness at a speed of $1.6 \mathrm{~m} / \mathrm{s}$. Blood samples were collected at four instances: during rest, immediately post-exercise, and then 30 minutes and five hours after the end of exercise. Plasma adropin and lactate concentrations (LA) were assessed. Only the intensive exercise significantly reduced the circulating level of adropin when compared with pre-exercise values $(p=0.001)$. Plasma adropin concentration was significantly reduced in response to high-intensive exercise.
\end{abstract}

Keywords: adropin, energy homeostasis, exercise, race horses

Citation: Kowalik S., Kédzierski W., Janczarek I., Wilk I. (2017) Plasma adropin in exercised horses: a pilot study. Pferdeheilkunde 33, 585-590; DOI 10.21836/PEM20170606

Correspondence: Sylwester Kowalik, PhD, Department of Animal Physiology, University of Life Sciences in Lublin, Akademicka 12, 20-033 Lublin, Poland; e-mail address: sylwester.kowalik@up.lublin.pl

\section{Introduction}

The maintenance of energy homeostasis in mammals is regulated by a complex network of peripheral and central signals that determine food intake and energy expenditure (Fortier et al. 2015, Gordon et al. 2007, Park et al. 2003). One of the newest, recently described peptides involved in this process is adropin. The preliminary study conducted by Kumar et al. [2008] indicates that adropin is a product of the Energy Homeostasis Associated Gene (Encho), identified in liver and brain tissues. The Encho genes coding adropin was initially identified in obese insulin-resistant mice and was described as a novel factor linking signals of nutrient intake with metabolic homeostasis (Kumar et al. 2008). Further studies showed that adropin is also expressed in heart and skeletal muscles, which could suggest adropin's role as a neuropeptide; however, the authors concluded that adropin plays an autocrine and/or paracrine role in peripheral tissues (Kumar et al. 2012, Gao et al. 2014, Shahjovei et al. 2016). Recently, adropin is classified as a hormone, with different sites of origin and types of local and/or systemic actions (Aydin 2014). Although the role of adropin in metabolic processes of energy homeostasis is still poorly understood, some results indicate that this hormone improves glucose homeostasis by reducing insulin resistance and glucose intolerance by responding to metabolic stress (Aydin 2007). Moreover, other studies suggest that adropin protects against obesity-associated hyperinsulinemia and hepatosteatosis by regulating both the lipid and glucose metabolism in the peripheral key-insulin target tissues, which include adipose tissue, liver and skeletal muscle (Kumar et al. 2008, Kumar et al. 2012, Frayn et al. 2007).

In physiological conditions, energy homeostasis is most difficult to balance during intensive exercise. For the maintenance of functional homeostasis under exercise, the endocrine system appears to play a crucial role in the mobilization of energy stores from the body's energy reservoirs (Frayn et al.
2003, Frühbeck et al. 2001). Regulation of energetic homeostasis is always multifactorial and involves energy balance regulating (EBR) hormones (Aydin 2014, Radin et al. 2009). These hormones include among others insulin, leptin, ghrelin, nesfatin-1, and adiponectin (Aydin 2013). Performed exercise influences the concentrations of EBR hormones based on its intensity and duration time (Ebal et al. 2007, Erdmann et al. 2007, Hagobian et al. 2008). Hence, the identification of these hormones may provide valuable information regarding the current state of energy balance (Gordon et al. 2007). Horses are domestic animals generally used for different kinds of work, such as classic equestrian sports, races, work in harness, and other kinds of work. However, among the EBR hormones, adropin in exercised horses has not been thoroughly studied. Therefore, the present study was designed to test the hypothesis that aerobic/anaerobic exercise and/or training are factors altering the plasma concentration of adropin in athletic horses.

\section{Material and Methods}

Horses

A total of 28 horses were included in the study. Twenty threeyear-old purebred Arabian horses (in equal numbers stallions and mares) were involved in race training (Group R). Eight Polish Konik stallions aged 5 to 10 years were used as draft horses for work in an agritourism farm (Group D). The horses were examined twice in one year, in May and September. At both times, the examination was done on two consecutive days: firstly, when the horses had a rest day (control), and secondly when they were submitted to exercise (exercise day). The animals were kept in individual boxes and were fed the diet recommended for working horses, including digestible energy $0.27 \mathrm{MJ} / \mathrm{kg} \mathrm{BW} /$ day and digestible protein $2.5 \mathrm{~g} / \mathrm{kg}$ BW/day, distributed over three feedings per day. 
The studied purebred Arabian horses were kept and trained in a race training centre. Every day, they were fed at 6 am, 12 $\mathrm{pm}$, and $6 \mathrm{pm}$. Before study, they were routinely exercised five to six times per week, according to the protocol recommended for race horses. The riders rode the horses at a walk and trot for approximately 10 minutes as a warm-up exercise. Then, the horses cantered or galloped on the sand track. The speed and duration of the run was individually adapted to the level of each horse's performance, in accordance with trainer's instructions. After the exercise, the horses were put on an automatic horse walker.

The Polish Konik horses were kept at the agritourism farm and were used for light draught. Their daily diet was distributed over feedings at $07.00 \mathrm{am}, 01.00 \mathrm{pm}$ and $06.00 \mathrm{pm}$. They were worked in a harness occasionally, at least two to five days a week for two to four hours per day.

\section{Protocol of examination}

The study on Group R was performed during the training sessions directly preceding the horses' official races, which means that the horses were in regular training at least two months in May and about six months in September. The horses were exercised on the dry sand racetrack between 08.00 and $10.00 \mathrm{am}$. under clear weather with an average temperature of around $18-20^{\circ} \mathrm{C}$. The schedule during testing days was as follows: after morning feeding, the horses were prepared for the training. Then, they were exercised in fours to prevent any effects of separation anxiety. They were selected to be in groups of four based on their similar racing performance. The training session included a 10- to 15-minute warm-up by walking and trotting on the sand-path leading to the racetrack as well as cantering and galloping over the distance of $1200 \mathrm{~m}$ at an average speed of $6-12 \mathrm{~m} / \mathrm{s}$, depending on the horse performance. On the days of the study, according to the instructions of the trainer, some horses galloped at a speed of $6-7 \mathrm{~m} / \mathrm{s}$, and others at a speed of $10-12 \mathrm{~m} / \mathrm{s}$. Therefore, they were divided into two sub-groups: horses which performed low-intensity exercise (sub-group R.L) and high-intensity exercise (sub-group R.H). After exercise on the track, all horses were cooled down in a horse walker for 30 minutes.

The horses from Group D were fed at $07.00 \mathrm{am}$, and one hour later they were harnessed and worked by carrying tourists for three hours, alternately walking and trotting, with average speed of $1.6 \mathrm{~m} / \mathrm{s}$. After the end of their work in harness, the horses were left freely on a paddock for about one hour.

On exercise days, four blood samples were collected from each horse, namely: TA- one hour after feeding, in their stalls when the horses were prepared to training session,

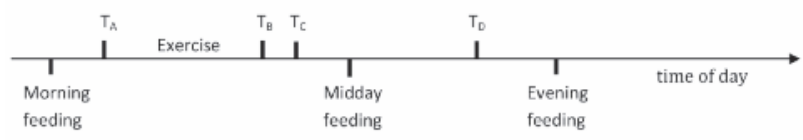

Fig. 1 Experiment schedule / scheme of blood sampling
TB - immediately after the end of the exercise, TC - 30 minutes after the end of the exercise, and TD - about six hours after the end of the exercise, in their stalls, before the evening feeding (Fig. 1).

During rest days, blood samples were collected three times: at 08:00 am (TA), 11:00 am (TBC) and 05:00 pm (TD).

Blood samples were obtained by jugular venipuncture directly to the vacuum tubes containing di-potassium EDTA (Vacutainer System, Becton-Dickinson Co., USA), and centrifuged at $1600 \times \mathrm{g}$ rate for 15 minutes at $4^{\circ} \mathrm{C}$. In samples obtained immediately after the exercise, lactic acid (LA) concentrations were determined using the enzymatic method (Cormay, Poland).

The remaining plasma was frozen and stored at $-70^{\circ} \mathrm{C}$ until the time of laboratory analysis of other biochemical parameters.

\section{Biochemical analysis}

Plasma concentration of adropin was measured in duplicate using a commercially available enzyme-immunoassay kit (Adropin ElA-kit, Phoenix Pharmaceuticals, Inc., Burlingame, USA), with a sensitivity at the level of $0.5 \mathrm{ng} / \mathrm{ml}$. The intraassay variations for the used kit was $<10 \%$. Data from the manufacturer indicated the specificity of adropin kit of $100 \%$ for humans, rats and mice. Serial dilutions of equine plasma demonstrated linearity and parallelism when they were plotted against the standard curve of serial dilution of used adropin standards. Two samples of equine plasma added to 1.0 and $10 \mathrm{ng} / \mathrm{ml}$ of adropin standards resulted in a $95 \%$ and $120 \%$ recovery of adropin standards, respectively. Results were expressed as human equivalents of immune-reactive adropin. Blood plasma LA concentrations were measured in duplicates using a colorimetric method and a DrLange portable analyzer (Dr. Lange Laboratory System LP450, Germany). The creatine kinase (CK) activities were estimated enzymatically by an automated system (Chemical Autoanalyzer BS120, Mindray, Shenzhen, China).

\section{Statistical analysis}

Statistical analyses were performed using the software GraphPad Prism 5 for Windows (GraphPad Software Inc., La Jolla, CA, USA). Effect measures were presented as means \pm standard deviation (SD) of the means. Statistical evaluation was done using two-way repeated measures ANOVA. The data were checked with regard to the normality of distribution using Shapiro-Wilk, Kolmogorov-Smirnov and Anderson-Darling tests. The tests did not reject the normal distribution hypothesis. Therefore, post hoc multiple comparisons were performed by Tukey's test. A value of $p=0.05$ was defined as statistically significant.

The relation between variables was analyzed with the multivariate correlation method using Pearson's test. There was compared plasma adropin concentration at rest (TA) with all biochemical parameters (TA, TB, TC and TD). Similarly, plasma adropin concentrations obtained at TB, TC and TD were compared with studied biochemical parameters, as mentioned above. 


\section{Results}

The results for adropin did not differ between May and September, meaning that the four-month training and/or racing season did not significantly influence the level of this hormone (data not tabulated). We decided to analyze the data obtained in May and September together, taking into consideration only the influence of exercise. Therefore, there are twice as many results than there were individual horses in the groups. The mean values of adropin obtained on rest days are presented in table 1. They were no significant timedependent differences in the investigated groups. In the exercised horses, significant differences were found in the subgroup R.H only (Tab. 2.). The plasma adropin concentration at TB was significantly lower than TA and TD. LA concentration in sub-group R.H at TB was significantly higher than stated in the other groups. Plasma CK activities measured on rest days did not differ significantly during the day (data not tabulated). Exercise involved significant increase in CK activities at TB and TC in comparison to TA and TD in Group D only (Tab. 2.). A significant ( $p$ 0.05) negative correlation ( $r=-$ 0.4) was found only between the resting values of adropin and post-exercised concentration of LA (TB).

\section{Discussion}

In this pilot report, it was clearly indicated that short-term intensive exercise resulted in decreases in plasma adropin concentration. In horses from subgroup R.H, the plasma adropin levels measured 30 minutes after the end of the training session were significantly lower than at rest. In the other groups, while the LA concentration did not exceed $2 \mathrm{mmol} / \mathrm{L}$, the adropin plasma concentration did not change during the study. Based on this observation, it is possible to consider that an anaerobic exercise decreased plasma adropin concentration whereas aerobic effort did not influence the level of this adipocytokine. Moreover, in rest days, there was no fluctuation in plasma adropin concentration in studied horses. It means that there were no diurnal fluctuations and changes in the plasma adropin concentration between meals in horses, similar like in humans (Butler et al. 2012).
In this study, we also compared the concentration of adropin between two consecutive training stages, namely in May, at the beginning of the training season, and in September, in the middle of the training season. Obtained results did not show significant influence of the time spent being trained on both the resting and post-exercised concentrations of adropin in horses. Similarly, no differences in plasma adropin concentrations were found in soccer players during consecutive phases of one-year-training (Sanchis-Gomar et al. 2015).

The few studies published up to now revealed that adropin regulates the preference for fuel selection in skeletal muscles in the feeding and fasting states (Gao et al. 2014, Aydin 2014). It activates the pyruvate dehydrogenase complex to increase glucose oxidation (Gao et al. 2014, Aydin 2014). Moreover, adropin increases non-oxidative glycolysis and LA production (Aydin 2014). On the other hand, adropin reduces muscle fatty acid oxidation by inhibiting carnitine palmitoyltransferase - a key enzyme that transports fatty acids into muscle mitochondria for -oxidation (Gao et al. 2014, McGarry and Brown 1997). Therefore, the observed decrease in plasma adropin concentration in exercised horses could promote oxidation of fatty acids in muscles over glucose utilization (Kédzierski et al. 2009). This is a positive aspect of how a horse's organism adapts to the performance of intensive exercise. It is known that in untrained horses, the activity of enzymes involved in the oxidation of fatty acids is low (Kédzierski et al. 2009). These enzymes activity in muscles increases with time spent training. Therefore, the oxidation of fatty acids would likely be low at the beginning of the training process, and would need to be stimulated via hormonal action. For example, in young horses, plasma leptin concentration

\begin{tabular}{|c|c|c|c|}
\hline Group of horses & $\mathrm{T}_{\mathrm{A}}$ & $\mathrm{T}_{\mathrm{BC}}$ & $\mathrm{T}_{\mathrm{D}}$ \\
\hline Group D $(n=16)$ & $10.21 \pm 0.91$ & $10.03 \pm 0.78$ & $9.94 \pm 0.68$ \\
\hline Group R $(n=16)$ & $7.94 \pm 0.67$ & $8.02 \pm 0.74$ & $8.09 \pm 0.62$ \\
\hline
\end{tabular}

\begin{tabular}{|c|c|c|c|c|c|}
\hline Groups of horses & $T_{1}$ & $T_{R}$ & $T_{1}$ & $T$ & . \\
\hline \multicolumn{6}{|c|}{ Adropin [ng/mL] } \\
\hline Group D & $10.71 \pm 1.00$ & $10.42 \pm 0.89$ & $10.33 \pm 0.88$ & $10.24 \pm 0.89$ & $>.05$ \\
\hline Sub-group R.L & $7.87 \pm 0.80$ & $7.90 \pm 0.64$ & $8.08 \pm 0.78$ & $8.13 \pm 0.82$ & $>.05$ \\
\hline Sub-group R.H & $8.05 \pm 0.88 a$ & $7.64 \pm 0.84 a b$ & $6.61 \pm 0.75 b$ & $8.40 \pm 0.89 a$ & .001 \\
\hline \multicolumn{6}{|c|}{$\mathrm{LA}[\mathrm{mmol} / \mathrm{L}]$} \\
\hline Group D & $0.78 \pm 0.11$ & $1.34 \pm 0.53$ & $0.96 \pm 0.14$ & $0.81 \pm 0.10$ & $>.05$ \\
\hline Sub-group R.L & $0.80 \pm 0.12$ & $1.14 \pm 0.41$ & $0.92 \pm 0.16$ & $0.77 \pm 0.13$ & $>.05$ \\
\hline Sub-group R.H & $0.82 \pm 0.12 a$ & $10.4 \pm 5.79 b$ & $1.92 \pm 0.83 c$ & $0.69 \pm 0.09 a$ & .001 \\
\hline \multicolumn{6}{|c|}{ CK [U/I] } \\
\hline Group D & $141 \pm 37.2 a$ & $231 \pm 170 b$ & $253 \pm 201 b$ & $167 \pm 142 a$ & .04 \\
\hline Sub-group R.L & $184 \pm 35.7$ & $244 \pm 64$ & $287 \pm 67.7$ & $212 \pm 51.8$ & $>.05$ \\
\hline Sub-group R.H & $226 \pm 63.1$ & $272 \pm 102$ & $278 \pm 118$ & $236 \pm 67.3$ & $>.05$ \\
\hline
\end{tabular}

Group D - draft horses ( $n=16)$, Sub-group R.L - race horses which performed low-intensity exercise $(n=16)$, Sub-group R.H - race horses which performed high-intensity exercise $(n=24)$. $T_{A}$ - blood samples collected at rest, $T_{B}-$ immediately after the end of exercise, $T_{C}-30$ min after the end of exercise, and $T_{D}$ - six hours after the end of exercise. $a, b, c-$ means in rows marked with different letters differ significantly at $p<0.05$. 
increased in response to intensive exercise (Kowalik and Kédzierski 2011 , Kédzierski 2016). Leptin stimulates lipolysis and oxidation of fatty acids. Thus, the increase in plasma leptin concentration promotes the utilization of lipids and energy production. The drop in plasma adropin concentration can probably play a similar role in exercised horses. Therefore, the changes in plasma adropin levels found in the study are a newly described physiological response of a young horse's organism to intensive exercise.

It was also found that plasma adropin concentrations determined at rest were negatively correlated with blood LA concentrations obtained after exercise. It means that horses with relatively high plasma adropin concentration showed a lower tendency of LA production. It is a known fact that LA is the product of non-oxidative glycolysis. High levels of LA decrease $\mathrm{pH}$ in muscle tissue and, as a result, muscle's ability to contraction. In race horses, well performed training should lead to decreases in LA synthesis during exercise. Thus, adropin could play a supplying role as an endogenous factor, promoting oxidative glycolysis in race horses, which would result in energy production over LA synthesis. However, to authenticate this statement, future studies performed on a higher number of horses exercised under aerobic and/or anaerobic conditions would be necessary.

There were no significant associations between adropin and CK values. It is known that plasma CK activity increases in exercised horses as a result of micro-injuries in skeletal muscles (Harris et al. 1998, Kédzierski 2011). The increase in plasma CK is higher after long-lasting effort than after shortterm, intensive exercise (Harris et al. 1998). Therefore, the exercise-induced increase in plasma CK activity was noted only in the group of draft horses that worked a few hours, and not in race horses that exercised at least a few minutes. Hence, the changes in CK activity were characteristic for the types of exercise that the horses performed (Harris et al. 1998, Kédzierski et al. 2006).

Although the present study has yielded some preliminary findings, its design is not without limitations. This study focuses mainly on the exercise as a general factor influencing the adropin level in horses. However, there might be some relevant factors, which additionally influence on the concentration of adropin in exercised horses, for example horse's breed, type of use and feeding routine. Therefore we did not compare the results obtained in purebred Arabian horses with these achieved in Polish Konik horses. And finally, there is the lack of similar investigations in a horse, hence it was not possible to discuss our results with others. Therefore, this preliminary study should be considered with caution, and further research is needed.

\section{Conclusions}

In summary, the results of the study indicate that only an intensive exercise decreased the level of circulating adropin. Low-intensive exercise did not influence the plasma adropin concentration. Based on the obtained results and reviewed literature it can be suppose that adropin likely plays a significant role in the regulation in energy expenditure.

\section{Animal welfare statement}

All procedures were conducted in accordance with the Guidelines for Animal Care and Treatment of the European Union, and were approved by the II Local Ethical Review Committee for Experiments on Animals at the University of Life Sciences in Lublin, Poland (No. 22.2009).

\section{References}

Aydin S. (2013) Presence of adropin, nesfatin-1, apelin-12, ghrelins and salusin peptides in the milk, cheese whey and plasma of dairy cows. Peptides 43, 83-87; DOI 10.1016/i.peptides.2013.02.014

Aydin S. (2014) Three new players in energy regulation: Preptin, adropin and irisin. Peptides 56, 94-110; DOI 10.1016/i.peptides.2014.03.021

Butler A. A., Tam C. S., Stanhope K. L., Wolfe B. M., Ali M. R., O'Keeffe M., St-Onge M. P., Ravussin E., Havel P. J. (2012) Low circulating adropin concentrations with obesity and aging correlate with risk factors for metabolic disease and increase after gastric bypass surgery in humans. J. Clin. Endocrinol. Metab. 97, 3783-3791; DOI 10.1210/jc.2012-2194

Ebal E., Cevalie H., Michaux O., Lac G. (2007) Effect of moderate exercise on the regulatory hormones of food intake in rats. Appetite 49, 521-524; DOI 10.1016/i.appet.2007.03.007

Erdmann J., Tahbaz R., Lippl F., Wagenpfeil S., Schusdziarra V. (2007) Plasma grelin levels during exercise - Effects of intensity and duration. Regul. Pept. 143, 127-135; DOI 10.1016/i.reqpep.2007.05.002

Fortier J., Deley G., Goachet A.-G., Julliand V. (2015) Quantification of the energy expenditure during training exercises in Standardbred trotters. Animal 9, 793-799; DOI 10.1017/ S1751731114003139

Frayn K. N., Karpe F., Fielding B. A., Macdonald I. A., Coppack S. W. (2003) Integrative physiology of human adipose tissue. Int. J. Obes. 27, 875-888; DOI 10.1038/s.ijio.0802326

Frayn K. N., Tan G. D., Karpe F. (2007) Adipose Tissue: A Key Target for Diabetes Pathophysiology and Treatment? Horm. Metab. Res. 39, 739-742; DOI 10.1055/s-2007-990270

Frühbeck G., Gómez-Ambrosi J., Muruzábal F. J., Burrell M. A. (2001). The adipocyte: a model for integration of endocrine and metabolic signaling in energy metabolism regulation. Am. J. Physiol. Endocrinol. Metab. 280, E827-E847

Gao S., McMillan R. P., Zhu Q., Lopaschuk G. D., Hulver M. W., But$\operatorname{ler} A$. A. (2015) Therapeutic effects of adropin on glucose tolerance and substrate utilization In diet-induced obese mice with insulin resistance. Mol. Metab. 4, 310-324; DOI 10.1016/j.molmet. 2015.01.005

Gao S., McMillan R. P., Jacas J., Zhu Q., Li X., Kumar G. K., Casals N., Hegardt F. G., Robbins P. D., Lopaschuk G. D., Hulver M. W., Butler A. A. (2014) Regulation of substrate oxidation preferences in muscle by the peptide hormone adropin. Diabetes 63, 3242-3252; DOI 10.2337/db14-0388

Gordon M. E., McKeever K. H., Betros C. L., Manso Philo H. C. (2007) Exercise-induced alterations in plasma concentrations of ghrelin, adiponectin, leptin, glucose, insulin, and cortisol in horses. Vet. J. 173,532-540; DOI 10.1016/i.tvil.2006.01.03

Hagobian T. A., Sharoff C. G., Braun B. (2008) Effects of short-term exercise and energy surplus on hormones related to regulation of energy balance. Metabolism 57, 393-398; DOI 10.1016/i.metabol.2007.10.016

Harris P. A., Marlin D. J., Gray J. (1998) Plasma aspartate aminotransferase and creatine kinase activities in Thoroughbred racehorses in relation to age, sex, exercise and training. Vet. J. 155, 295-304; DOI 10.1016/S1090-0233(05)80026-7

Kédzierski W. (2016) Leptin fluctuations on trained horses during a work season. J. Equine Vet. Sci. 43, 12-17; DOI 10.1016/i.jevs. 2016.04.094 
Kédzierski W. (2011) Correlation of plasma creatine kinase activity and glucose level in exercised Purebred Arabian horses. Medycyna Weter. 67, 541-544

Kédzierski W., Bergero D., Assenza A. (2009) Trends of hematological and biochemical values in blond of young race horses during standardized field exercise test. Acta Vet. Beograd 59, 457-466; DOI 10.2298/AVB0906457K

Kédzierski W., Bergero D. (2006) Comparison of plasma biochemical parameters in Thoroughbred and Purebred Arabian horses during the same-intensity exercise. Polish J. Vet. Sci. 9, 233-238

Kowalik S., Kédzierski W. (2011) The effect of interval versus continuous exercise on plasma leptin and grelin concentration in young trotters. Polish J. Vet. Sci. 14, 373-378

Kumar K. G., Trevaskis J. L., Lam D. D., Sutton G. M., Koza R. A., Chouljenko V. N., Kousoulas K. G., Rogers P. M., Kesterson R. A., Thearle M., Ferrante A. W. Jr., Mynatt R. L., Burris T. P., Dong J. Z., Halem H. A., Culler M. D., Heisler L. K., Stephens J. M., Butler A. A. (2008) Identification of adropin as a secreted factor linking dietary macronutrient intake with energy homeostasis and lipid metabolism. Cell Metab. 8, 468-481; DOI 10.1016/i.cmet.2008. 10.011

Kumar K. G., Zhang J., Gao S., Rossi J., McGuinness O. P., Halem H. H., Culler M. D., Mynatt R. L., Butler A. A. (2012) Adropin defi- ciency in associated with increased adiposity and insulin resistance. Obesity 20, 1394-1402; DOI 10.1038/oby.2012.31

McGarry J. D., Brown N. F. (1997) The mitochondrial carnitine palmitoyltransferase system. From concept to molecular analysis. Eur. J. Biochem. 277, 1-14; DOI 10.1111/j.1432-1033.1997. $00001 . x$

Park H. B., Marklund S., Jeon J. T., Mickelson J. R., Valberg S. J., Sandberg K., Andersson L. (2003) Molecular characterization and mutational screening of the PRKAG3 gene in the horse. Cytogenet. Genome Res. 102, 211 -216; DOI 10.1159/000075751

Radin M. J., Sharkey L. C., Holycross B. J. (2009) Adipokines: a review of biological and analytical principles and an uptade in dogs, cats, and horses. Vet. Clin. Pathol. 38, 136-156; DOI 10.1111/j.1939-165x.2009.00133.x

Sanchis-Gomar F., Alis R., Rampinini E., Bosio A., Ferioli D., La Torre A., XU J., Sansoni V., Perego S., Romagnoli M., Lombardi G. (2015) Adropin and apelin fluctuations throughout a season in professional soccer players: Are they related with performance? Peptide 70, 32-36; DOI 10.1016/i.peptides.2015.05.001

Shahjouei S., Ansari S., Pourmotabbed T., Zand R. (2016) Potential roles of adropin in central nervous system: review of current literature. Front. Mol. Biosci. 3, 1-8; DOI 10.3389/fmolb. 2016.00025 